\title{
Incidental imaging findings of congenital rib abnormalities: a case series and review of developmental concepts
}

\author{
A.M. Aignătoaei ${ }^{1}$, C.E. Moldoveanu², I.-D. Căruntu³, S.E. Giuşcă³ \\ S. Partene Vicoleanu ${ }^{3}$, A.H. Nedelcu ${ }^{3}$ \\ ${ }^{1}$ Department of Pathology, "Sf. Spiridon" Clinic Hospital, 1, Independenței Square, Iaşi, Romania \\ ${ }^{2}$ Department of Radiology, Pneumology Clinic Hospital, 30, dr. losif Cihac Street, laşi, Romania \\ ${ }^{3}$ Department of Morphofunctional Sciences, "Grigore T. Popa" University, 16, University Street, laşi, Romania
}

[Received: 12 June 2017; Accepted: 24 July 2017]

Background: Congenital rib abnormalities are found in approximately $2 \%$ of the general population. Usually, they occur in isolation and are rarely symptomatic, but they can also be associated with other malformations.

Materials and methods: We reviewed imaging examinations performed over a period of 2 years (2014-2015), enabling us to identify isolated rib abnormalities in 6 adult patients.

Results: The case series consisted in 3 cases with bilateral cervical ribs and 1 case each with bifid rib, costal fusion and rib pseudarthrosis. In all patients, the costal anomalies were discovered incidentally. All rib malformations were detected at thoracic radiography, except for the rib pseudarthrosis, which was identified at computed tomography (CT) scan. Differential diagnosis was made between cervical ribs and abnormalities of the $\mathrm{C} 7$ transverse process and of the first rib, while the other costal malformations were distinguished from tumoural, traumatic or inflammatory lesions of the chest wall, lung and pleura. Considering the existing knowledge on rib development, we suggest a classification of the most common types of rib malformations in three categories: (I) results of homeotic transformation, referring to numerical aberrations; (II) segmentation errors, including costal fusion and bridging; (III) anomalies of resegmentation, resulting in bifid ribs.

Conclusions: It is important that radiologists are familiarised with the imaging features of rib abnormalities, since these anomalies can be misinterpreted as lesions with different implications. We are convinced that the developmental classification proposed in this paper can contribute to a better understanding of this pathology. (Folia Morphol 2018; 77, 2: 386-392)

Key words: rib malformations, classification, homeotic transformation, segmentation, resegmentation 


\section{INTRODUCTION}

Abnormalities in the number and structure of ribs are found in approximately $2 \%$ of the general population $[5$, 29], even though their prevalence can be variable among different ethnic categories $[23,24]$ or age groups $[11,19]$.

Congenital anomalies of the ribs can occur as single malformations or in association with other abnormalities [29]. However, the majority of congenital rib anomalies appear as isolated findings [5-7], mostly asymptomatic $[8,10]$.

There is a wide spectrum of morphologic variants of rib abnormalities and unfortunately, in most instances, the boundary between malformation and anatomical variation remains unclear [26]. Isolated rib malformations are considered by some authors "normal variants" $[10,31]$ and mainly include supernumerary ribs (cervical, lumbar), bifid ribs, rib synostosis and aplasia of the ribs [5, 31]. Frequently, these rib anomalies are reported in the publication mainstream as single cases or case series that refer to the same type of abnormality. There are few studies that analyse a larger number of cases and morphologic variants, to determine their prevalence or their association with other malformations or certain pathological conditions $[19,29]$. To the best of our knowledge though, a classification of the main types of congenital rib anomalies, based on the underlying developmental defect, hasn't yet been made.

The occurrence of congenital rib anomalies is strongly linked to the alteration of rib development during embryogenesis. Ribs, as part of the axial skeleton, originate in the somites, paired structures located on the dorsal side of the embryo, along the rostrocaudal axis [18]. Depending on its position, each somite will give rise to specific structures, adapted to their function. This is reflected in the distinct morphology of vertebrae in each region and in the formation of ribs alongside the thoracic vertebrae. The positional identity of each somite is predetermined before it emerges as a distinct structure. This information is under the control of the Hox gene family $[1,16,18]$.

Somites are formed through the process of segmentation, in which clusters of mesenchymal cells are detached from the presomitic mesoderm in gradual manner, starting from the cranial end and extending towards the caudal extremity of the embryo [1]. The segmental border of a somite is defined under the influence of Mesp2, a transcription factor that acts by suppressing the Notch signalling pathway [20], involved in the pace of somite formation [1].
Somites will further go through the process of resegmentation, in which each one will divide in one rostral half and one caudal half. Mesp2 also plays a crucial role in defining these regions, by establishing the gene expression pattern within the two halves [25]. The formation of a rib follows a complex pattern that involves the caudal half and the rostral half of two adjacent somites $[2,18]$.

Our study presents a case series of incidentally discovered congenital rib malformations, aiming to point out their imaging features and to raise awareness on the existence of these common variations. Furthermore, based on the existing data in developmental biology, we propose a classification of isolated congenital rib abnormalities, according to the causative embryologic defect.

\section{MATERIALS AND METHODS}

From a total number of 11,853 imaging examinations $(11,538$ chest radiographs and 315 computed tomography [CT] scans) performed at a county pneumology hospital over a period of 2 years (2014-2015), a number of six cases of isolated congenital rib anomalies ( 5 of them discovered on chest $X$-rays and 1 on helical CT scan) was identified. The images were acquired with a Siemens Multix Select DR digital X-ray equipment, respectively with a Siemens Somatom Emotion $16 \mathrm{CT}$ scanner and they were processed by Radiant DICOM Viewer, respectively K-PACS software. In all of these cases, the costal anomalies were found incidentally. The study was approved by the Ethics Committee of the Pneumology Clinic Hospital.

\section{RESULTS}

\section{Radiologic aspects of the case series}

We identified four morphologic variants of congenital rib anomalies, respectively cervical ribs (in 3 cases), bifid rib (in 1 case), costal fusion (in 1 case) and rib pseudarthrosis (in 2 case).

\section{Case 1}

A healthy, 30-year-old male patient underwent a thoracic radiography required for employment procedures. When examining the posteroanterior plain film, we identified the presence two bilateral osseous, rib-like structures that were jointed with the $\mathrm{C} 7$ transverse processes and followed an anterior and inferior course (Fig. 1). These features attested the presence of bilateral cervical ribs. They were of medium size (approximately $6 \mathrm{~cm}$ ), didn't reach to articulate with 


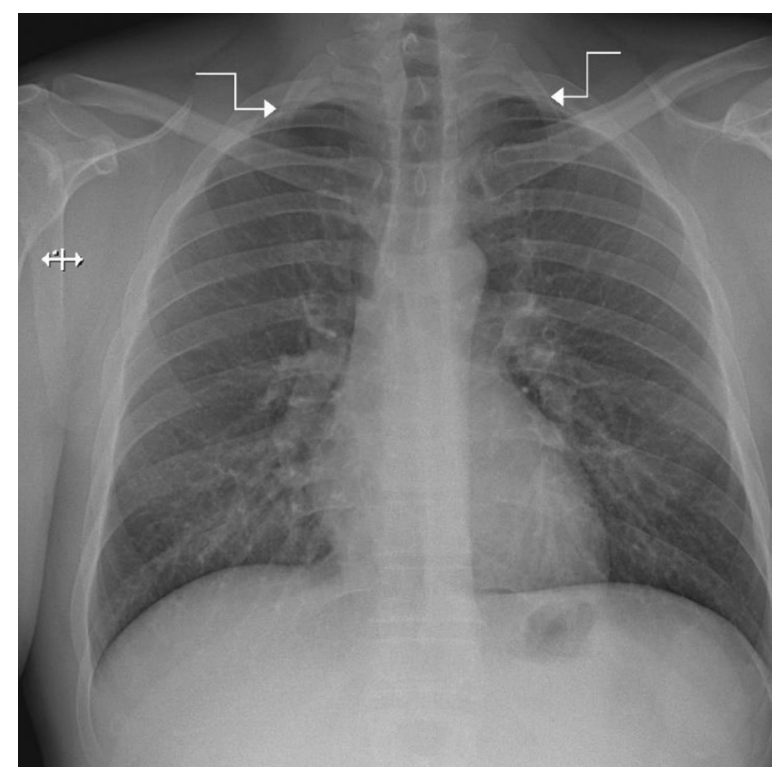

Figure 1. Bilateral cervical rib. Thoracic radiography, posteroanterior view - case 1.

the sternum and they were relatively symmetrical in length and thickness. The patient never suffered from any symptoms related to the costal anomaly. No pulmonary or mediastinal abnormalities were identified.

\section{Case 2}

A 55-year-old man was investigated during a routine health check, when the chest radiography in posteroanterior incidence revealed the presence of bilateral cervical ribs (Fig. 2). The right cervical rib was of medium size (approximately $6 \mathrm{~cm}$ ) and didn't reach the sternum. The left cervical rib was obviously shorter (approximately $3 \mathrm{~cm}$ ), with the small length of a rudimentary rib. The costal malformation was never clinically manifest in the patient. No changes were identified in the pulmonary or mediastinal areas.

\section{Case 3}

A healthy, 20-year-old female patient was referred to chest radiography on account of university admission procedures. The posteroanterior plain film revealed the presence of bilateral cervical ribs of medium size, neither of them reaching the sternum (Fig. 3). The cervical ribs had similar lengths (approximately $5 \mathrm{~cm}$ ), but the left one was slightly thinner that the right one $(0.4 \mathrm{~cm}$ vs. $0.7 \mathrm{~cm})$. The patient had no symptoms due to this anomaly. No pulmonary or mediastinal abnormalities were identified.

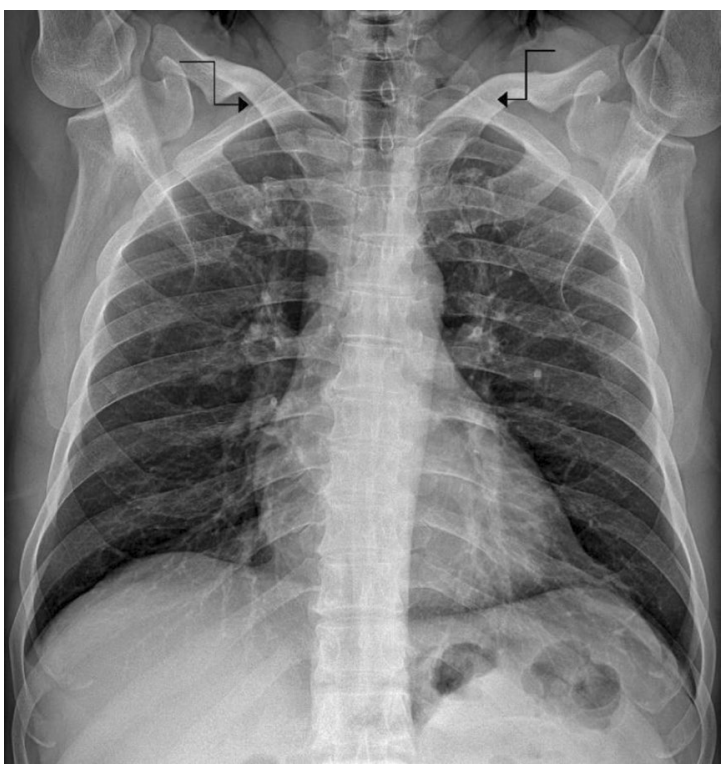

Figure 2. Bilateral cervical rib. Thoracic radiography, posteroanterior view - case 2 .

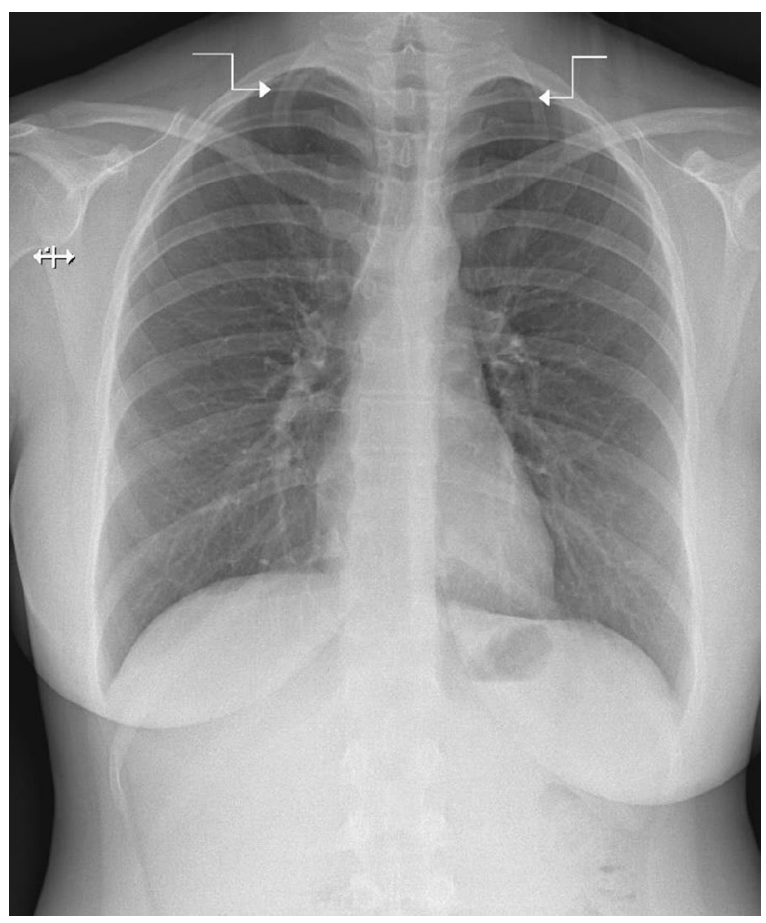

Figure 3. Bilateral cervical rib. Thoracic radiography, posteroanterior view - case 3 .

\section{Case 4}

A routine chest radiography was performed in a 37-year-old male patient with no significant personal history. On careful examination of the rib cage, on both posteroanterior and lateral incidences we 


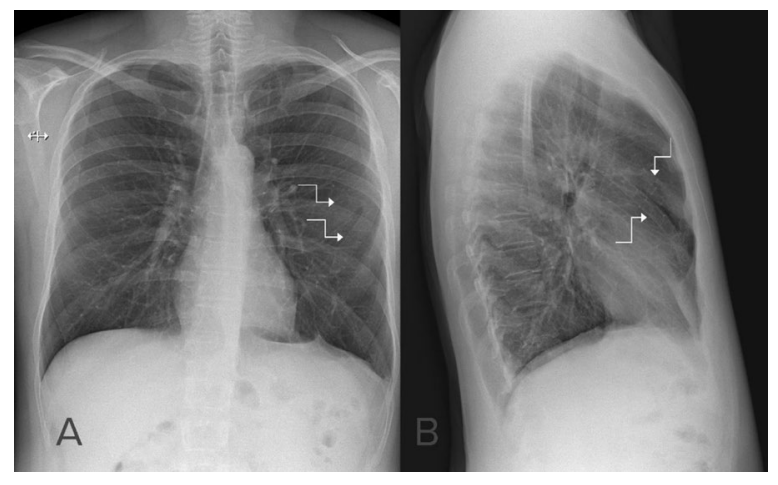

Figure 4. Fourth bifid rib, thoracic radiography; A. Posteroanterior view; B. Lateral view.

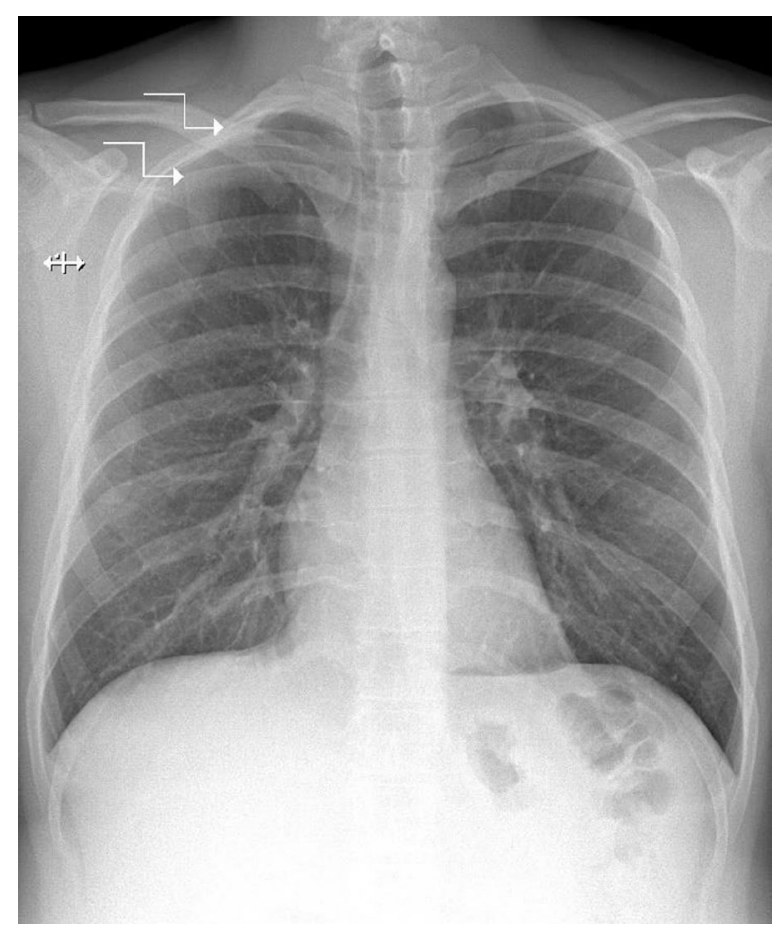

Figure 5. Costal fusion between the first and second ribs. Thoracic radiography, posteroanterior view.

observed that the left fourth rib was bifurcated in its anterior portion, with its two branches delimitating a slender, V-shaped space (Fig. 4). This finding witnessed the presence of a bifid rib. The patient had no signs or symptoms related to the costal abnormality. No pulmonary or mediastinal abnormalities were identified.

\section{Case 5}

A 25-year-old male patient suffering from severe respiratory symptoms, due to a tracheo-bronchitis, underwent chest radiography to exclude the pulmonary involvement. No changes were detected in the pulmonary or mediastinal areas, but when inspecting the rib cage, we noticed that the first and second ribs of the right hemithorax were partially fused in their middle portions (Fig. 5). The costal synostosis gave no clinical symptoms to the patient.

\section{Case 6}

A 40-year-old female patient underwent an unenhanced thoracic CT scan, after the presence of a pulmonary nodule in the left superior lobe was suspected on a chest radiograph. The CT scan images were processed in multiplanar and three-dimensional reconstructions. No changes were identified in the pulmonary window, but in the bone window, we identified an osseous bridge between the first and second ribs of the left hemithorax. The costal bridge was situated between the anterior portions of the two ribs and it was formed by two bone outgrows that joined into a pseudarthrosis (Fig. 6). The patient had no history of trauma, so we concluded it was a congenital abnormality. She never had any symptoms caused by this costal anomaly. No other changes within the thoracic area were identified.

\section{DISCUSSION}

Isolated rib anomalies can be easily missed on standard chest radiographies. Better visualisation of rib abnormalities is achieved with $\mathrm{CT}$ or magnetic resonance imaging (MRI) examinations [27, 28]. However, the radiologist's experience is decisive. Therefore, it is worth mentioning that in our series the costal malformations were identified on standard thoracic radiographies in posteroanterior or lateral views, except for one, that was only obvious on CT examination.

Bilateral cervical ribs were easily identified on plain chest films in three of our patients. The differential diagnosis was made with atypical first ribs and with elongated transverse processes of the $\mathrm{C} 7$ vertebrae, considering the position, size and the existent joint between the rib and the vertebrae.

It is important for radiologists to identify cervical ribs, since these relatively common anomalies can cause a thoracic outlet syndrome in $10 \%$ of the cases [15]. Moreover, it was shown that these anomalies go undetected in $74.6 \%$ of the CT scans [27]. Based on radiographic investigations, various incidences $(0.05-3 \%)$ of cervical ribs were reported [27]. How- 


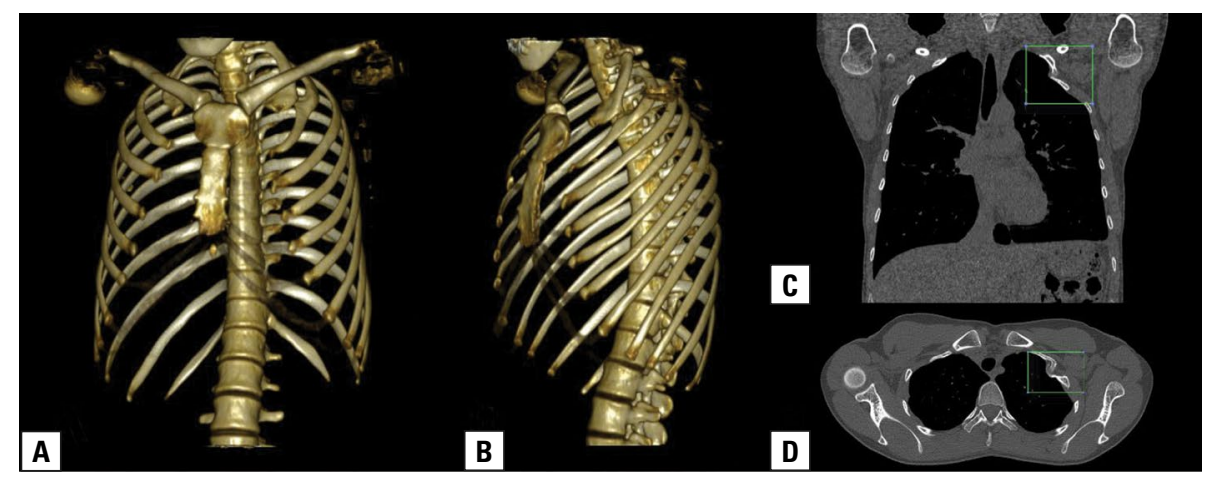

Figure 6. Rib pseudarthrosis between the first and second ribs, computed tomography scan; A, B. Three-dimensional reconstructions; C. Coronal section; D. Transverse section.

ever, more recent studies performed on large cohorts, using imaging explorations of higher accuracy such as spiral CT [27] or MRI [28] revealed rates of $2 \%$ and respectively $1.2 \%$. Cervical ribs were found bilaterally in $40.3 \%$ of the cases identified by CT scan [27].

The bifid rib encountered in one of the patients was also visible on standard chest radiography. In this case, we had to make differential diagnosis with a chest wall tumour or a costal fracture, which were excluded through detailed examination of the posteroanterior and lateral views and through the patient's history and clinical exam.

The prevalence of bifid ribs in the general population ranges between $0.15 \%$ and $3.4 \%$ [12]. As in our case, the fourth rib is most frequently involved [8]. This malformation is usually asymptomatic and requires no additional intervention, or it may present as a painless mass located on the thoracic wall [12, 23]. Therefore, it is useful to identify this innocuous costal malformation, in order to differentiate it from other more harmful conditions, such as the ones we mentioned above. In this regard, it was shown that echography allows a better evaluation of the bifid ribs compared to chest X-ray [14].

Rib synostosis can be seen in the form of fusion or bridging, the latter possibly joined in a pseudarthrosis. Our case series illustrates an example of each category, both situated between the first and second ribs. The first costal malformation was visible on chest radiography, while the other one was only detected through CT scan evaluation. In these cases, we had to make differential diagnosis with lung or pleural lesions (pulmonary nodule, non-systemised pulmonary opacity, pachypleuritis, encapsulated pleurisy, pleural tumour) or with a chest wall neoplasia, by carefully examining the lateral view X-ray and CT scan images, respectively.

The rates of costal fusion and rib pseudarthrosis in the general population were reported as $0.3 \%$ [9] and $0.1 \%$ [31], respectively. These anomalies frequently occur in the first two ribs $[5,31]$, where they can be visible on clinical inspection as a deformity at the thoracic aperture, possibly causing a thoracic outlet syndrome [13, 22]. It is important that radiologists are aware of these rare costal malformations, so as to differentiate them from various other lesions mentioned before and to indicate the appropriate therapeutic management, in case they become compressive at the thoracic outlet.

Among all types of congenital rib malformations, supernumerary ribs (cervical or lumbar), aplasia of the ribs and segmentation defects (bifidity, fusion and bridging) are the most common varieties, accounting for $30 \%, 26 \%$ and $20 \%$ of all costal abnormalities, respectively $[5,29]$. According to the underlying developmental defect, we propose a classification of these morphologic variants in three major classes, as follows: (I) results of homeotic transformation, referring to numerical aberrations of the ribs; (II) segmentation errors that include costal fusion and bridging; (III) anomalies of resegmentation, resulting in bifid ribs (Table 1).

Homeotic transformation of a vertebra refers to changing its positional identity, as a result of abnormal expression of the homeobox (Hox) genes [18]. These transformations occur more frequently at the transition between the vertebral regions, respectively at the cervico-thoracic and thoraco-lumbar boundaries, affecting the number of ribs [18]. Experimental studies have shown that abnormal expression of Hoxa-4 
Table 1. A proposal for developmental classification of rib anomalies

\begin{tabular}{ll}
\hline Type & Mechanism \\
\hline I & Results of homeotic transformation: \\
& a. Supernumerary ribs (cervical, lumbar) \\
& b. Aplastic rib \\
\hline II & Segmentation errors: \\
& a. Costal fusion \\
& b. Costal bridges \\
\hline III & Anomalies of resegmentation: \\
& Bifid ribs \\
\hline
\end{tabular}

and Hoxa-5 genes results in transformation of the seventh cervical vertebra into a thoracic vertebra and subsequent formation of cervical ribs [16]. Similarly, inactivation of the Hox group 10 led to the appearance of ribs in the lumbar region, demonstrating the involvement of these genes in establishing the lumbar vertebral phenotype [30]. Homeobox genes also play a role in tumour suppression and carcinogenesis, since both development and neoplasia juggle with cell proliferation and differentiation $[4,21]$. This can explain the association between an abnormal number of ribs and cancer, proven by studies in which cervical ribs and subnumerary ribs (less than 24) are correlated with childhood neoplasia [7]. In our opinion, this data justifies enclosing supernumerary (cervical and lumbar) and aplastic ribs in a distinct developmental category, as results of homeotic transformations.

It is thought that fused ribs and bifid ribs are both results of segmentation defects during somitogenesis $[5,29]$, but new experimental studies, performed on animal embryos, suggest that these two types of malformations occur through different mechanisms.

In a study that focused on the Mesp2 transcription factor, it was shown that a decreased level of expression of Mesp2 determines the apparition of fused ribs, with a higher frequency as the amount of Mesp2 is lower [20]. Since Mesp2 plays an essential role in the processes of segmentation, these outcomes further support the fact that rib synostoses result from segmentation anomalies, which determined us to place them in this developmental category.

Regarding bifid ribs, researches on chick embryos showed that this type of defect appears when interfering with the process of resegmentation [2]. When one somite half was transplanted in the place of an entire somite, rendering one missing half, the embryos resulted with rib duplications [2]. These outcomes suggest that bifid ribs appear when the union between the halves of two adjacent somites is compromised. The involvement of this developmental error in the appearance of bifid ribs is also mentioned in other scientific papers $[3,17]$. For this reason, we decided to place bifid ribs in a distinct category of our classification, as defects of resegmentation.

\section{CONCLUSIONS}

Congenital rib anomalies are not unusual findings in radiological practice. It is useful that radiologists are familiarised with the imaging appearance of these malformations, since they can be misread as tumoural, traumatic or inflammatory lesions of the chest wall, lungs or pleura. Nevertheless, these anomalies reflect some disturbances during the embryo development, leading us to propose a potential classification that could contribute to a better understanding of this pathology.

\section{REFERENCES}

1. Aulehla A, Pourquié O. Signaling gradients during paraxial mesoderm development. Cold Spring Harb Perspect Biol. 2010; 2(2): a000869, doi: 10.1101/cshperspect.a000869, indexed in Pubmed: 20182616.

2. Aoyama H, Asamoto K. The developmental fate of the rostral/caudal half of a somite for vertebra and rib formation: experimental confirmation of the resegmentation theory using chick-quail chimeras. Mech Dev. 2000; 99(1-2): 71-82, indexed in Pubmed: 11091075.

3. Basarslan F, Bayarogulları H, Tutanc M, et al. Intrathoracic rib associated with pulmonary collapse in a pediatric patient. Iran J Radiol. 2012; 9(4): 220-222, doi: 10.5812/ iranjradiol.8608, indexed in Pubmed: 23408171.

4. Bots J, Wijnaendts LCD, Delen S, et al. Analysis of cervical ribs in a series of human fetuses. J Anat. 2011; 219(3): 403-409, doi: 10.1111/j.1469-7580.2011.01400.x, indexed in Pubmed: 21689099.

5. Castriota-Scanderbeg A, Dallapiccola B. Abnormal Skeletal Phenotypes: From Simple Signs to Complex Diagnoses. Springer, New York. 2005: 124-144.

6. Cosson MA, Breton S, Aprahamian A, et al. [Unusual presentation of rib malformation]. Arch Pediatr. 2012; 19(11): 1208-1211, doi: 10.1016/j.arcped.2012.08.023, indexed in Pubmed: 23037576.

7. Gindes L, Benoit B, Pretorius DH, et al. Abnormal number of fetal ribs on 3-dimensional ultrasonography: associated anomalies and outcomes in 75 fetuses. J Ultrasound Med. 2008; 27(9): 1263-1271, indexed in Pubmed: 18716135.

8. Glass RBJ, Norton KI, Mitre SA, et al. Pediatric ribs: a spectrum of abnormalities. Radiographics. 2002; 22(1): 87-104, doi: 10.1148/radiographics.22.1.g02ja1287, indexed in Pubmed: 11796901. 
9. Gupta V, Suri RK, Rath G. Synostosis of first and second thoracic ribs: Anatomical and radiological assessment. IJAV. 2009; 2: 131-133.

10. Guttentag AR, Salwen JK. Keep your eyes on the ribs: the spectrum of normal variants and diseases that involve the ribs. Radiographics. 1999; 19(5): 1125-1142, doi: 10.1148/radiographics.19.5.g99se011125, indexed in Pubmed: 10489169.

11. Hershkovitz R. Prenatal diagnosis of isolated abnormal number of ribs. Ultrasound Obstet Gynecol. 2008; 32(4): 506-509, doi: 10.1002/uog.5296, indexed in Pubmed: 18537105.

12. Kaneko $H$, Kitoh $H$, Mabuchi $A$, et al. Isolated bifid rib: clinical and radiological findings in children. Pediatr Int. 2012 54(6): 820-823, doi: 10.1111/j.1442-200X.2012.03672.x, indexed in Pubmed: 22640412.

13. Kirschbaum A, Palade E, Csatari Z, et al. Venous thoracic outlet syndrome caused by a congenital rib malformation. Interact Cardiovasc Thorac Surg. 2012; 15(2): 328-329, doi: 10.1093/icvts/ivs141, indexed in Pubmed: 22544354.

14. Kryger M, Kosiak W, Batko T. Bifid rib - usefulness of chest ultrasound. A case report. J Ultrason. 2013; 13(55): 446-450, doi: 10.15557/JoU.2013.0048, indexed in Pubmed: 26675170

15. Leong SC, Karkos PD. A "hard" neck lump. Singapore Med J. 2009; 50(4): e141-e142, indexed in Pubmed: 19421669.

16. Li Z, Kawasumi M, Zhao B, et al. Transgenic over-expression of growth differentiation factor 11 propeptide in skeleton results in transformation of the seventh cervical vertebra into a thoracic vertebra. Mol Reprod Dev. 2010; 77(11): 990-997, doi: 10.1002/mrd.21252, indexed in Pubmed: 21049546.

17. Mahajan PS, Hasan IA, Ahamad N, et al. A unique case of left second supernumerary and left third bifid intrathoracic ribs with block vertebrae and hypoplastic left lung. Case Rep Radiol. 2013; 2013: 620120, doi: 10.1155/2013/620120, indexed in Pubmed: 24416613.

18. Mallo M, Vinagre T, Carapuço $M$. The road to the vertebral formula. Int J Dev Biol. 2009; 53(8-10): 1469 -1481, doi: 10.1387/ijdb.072276mm, indexed in Pubmed: 19247958.

19. Merks JHM, Smets AM, Van Rijn RR, et al. Prevalence of rib anomalies in normal Caucasian children and childhood cancer patients. Eur J Med Genet. 2005; 48(2) 113-129, doi: 10.1016/j.ejmg.2005.01.029, indexed in Pubmed: 16053903.

20. Morimoto M, Kiso M, Sasaki N, et al. Cooperative Mesp activity is required for normal somitogenesis along the anterior-posterior axis. Dev Biol. 2006; 300(2): 687-698, doi: 10.1016/j.ydbio.2006.08.043, indexed in Pubmed: 16996494.

21. Nunes FD, de Almeida FC, Tucci R, et al. Homeobox genes: a molecular link between development and cancer. Pesqui Odontol Bras. 2003; 17(1): 94-98, indexed in Pubmed: 12908068.

22. Reidler JS, Das De S, Schreiber JJ, et al. Thoracic outlet syndrome caused by synostosis of the first and second thoracic ribs: 2 case reports and review of the literature. J Hand Surg Am. 2014; 39(12): 2444-2447, doi: 10.1016/j. jhsa.2014.08.034, indexed in Pubmed: 25307506.

23. Song WC, Kim SH, Park DK, et al. Bifid rib: anatomical considerations in three cases. Yonsei Med J. 2009; 50(2): 300-303, doi: 10.3349/ymj.2009.50.2.300, indexed in Pubmed: 19430569.

24. Stevenson RE, Hall JG. Human malformations and related anomalies, second edition. Oxford, New York. 2005: 812-813.

25. Takahashi Yu, Yasuhiko Y, Takahashi J, et al. Metameric pattern of intervertebral disc/vertebral body is generated independently of Mesp2/Ripply-mediated rostro-caudal patterning of somites in the mouse embryo. Dev Biol. 2013; 380(2): 172-184, doi: 10.1016/j.ydbio.2013.05.020, indexed in Pubmed: 23727513.

26. Tyl RW, Chernoff N, Rogers JM. Altered axial skeletal development. Birth Defects Res B Dev Reprod Toxicol. 2007; 80(6): 451-472, doi: 10.1002/bdrb.20134, indexed in Pubmed: 18157900.

27. Viertel VG, Intrapiromkul J, Maluf F, et al. Cervical ribs: a common variant overlooked in CT imaging. AJNR Am J Neuroradiol. 2012; 33(11): 2191-2194, doi: 10.3174/ ajnr.A3143, indexed in Pubmed: 22790240.

28. Walden MJ, Adin ME, Visagan R, et al. Cervical ribs: identification on MRI and clinical relevance. Clin Imaging. 2013; 37(5): 938-941, doi: 10.1016/j.clinimag.2013.01.005, indexed in Pubmed: 23759210.

29. Wattanasirichaigoon D, Prasad C, Schneider G, et al. Rib defects in patterns of multiple malformations: a retrospective review and phenotypic analysis of 47 cases. Am J Med Genet A. 2003; 122A(1): 63-69, doi: 10.1002/ ajmg.a.20241, indexed in Pubmed: 12949975.

30. Wellik DM, Capecchi MR. Hox10 and Hox11 genes are required to globally pattern the mammalian skeleton. Science. 2003; 301(5631): 363-367, doi: 10.1126/science.1085672, indexed in Pubmed: 12869760.

31. Yochum TR, Rowe $\amalg .2005$. Essentials of skeletal radiology, third edition. Lippincott/Williams \& Wilkins, Philadelphia 2005: 291-293: 319-324. 